JIP, Vol.8, No. 1, Edisi Januari 2018, Hal: 13-23

Didik Iswahyudi, Mochammad Ramli Akbar

\title{
Peningkatan Kemampuan Komunikasi Mahasiswa Melalui Metode Student Team Achievement Division (STAD) Berbasis Lesson Study For Learning Community (LSLC)
}

\author{
Didik Iswahyudi ${ }^{1}$, Mochammad Ramli Akbar ${ }^{2}$ \\ Universitas Kanjuruhan Malang \\ didik@unikama.ac.id ${ }^{1}$ \\ ramli_akbar@unikama.ac.id ${ }^{2}$
}

\begin{abstract}
Abstrak
Penelitian ini dilakukan untuk meningkatkan kemampuan komunikasi mahasiswa Pancasila dan Kewarganegaraan (PPKn) melalui metode pada Lesson Study for Learning Community (LSLC) dengan cara diskusi dan debat dengan tema teori Demokrasi untuk 6 (enam) pertemuan atau siklus Penelitian Tindakan Kelas, dengan menggunakan rencana pelajaran dan rancangan bab yang dikembangkan bersama dengan tim pengembangan kurikulum program studi PPKn. Berdasarkan penelitian yang dilakukan, kesimpulan yang dapat ditarik adalah: (1) Lesson study mampu memberi efek secara positif bagi siswa dan dosen pada proses pembelajaran yang meningkat dari pertemuan ke pertemuan. (2) Kegiatan diskusi dan debat dalam kegiatan Lesson Study dari siklus I sampai dengan VI mengalami peningkatan yang signifikan, mulai dari pembahasan pasif sampai debat sengit berdasarkan pertimbangan yang mulai bersifat empiris terhadap Teori Demokrasi. (3) Kelompok siswa telah meningkat, mulai dari diskusi pasif dan didominasi oleh satu kelompok, untuk diperdebatkan dengan kemampuan yang setara di semua kelompok. (4) Nomenklatur kelas dan volume yang lebih representatif sehingga diskusi dan debat lebih efektif dan efisien untuk proses pembelajaran yang baik.

Kata kunci: kemampuan komunikasi, student team achievement division, lesson study for learning community
\end{abstract}

\footnotetext{
Abstract

This research was conducted to improve the communication ability of Pancasila and Citizenship Education (PPKn) Students through Student Team Achievement Division (STAD) method based on Lesson Study for Learning Community (LSLC) with discussion and debate on the subject of Democracy Theory for 6 (six) meetings or Classroom Action Research cycle, using lesson plan and chapter design that was developed together with the curriculum development team of PPKn study program. Based on the research conducted, the conclusions can be drawn are: (1) Lesson study able to give positive effect to the students and lecturers on the learning process that increase from meeting to meeting. (2) Discussion and debate activities in Lesson Study activities from cycle I to VI have significant improvement, ranging from passive discussion to heated debate on the basis of consideration that began empirical on the subject of Democratic Theory. (3) Group or group of students has increased, ranging from passive discussion and dominated by one group, to debate with equal ability in all groups. (4) A more representative class of nomenclature and volume so that discussion and debate are more effective and efficient for good learning process.

Keywords: communication skills, student team achievement division, lesson study for learning community
} 
PENDAHULUAN

Secara esensi, cara dan proses, untuk menyuarakan pendapat adalah hak semua orang dengan mekanisme yang sudah diatur dengan norma dan cara menyampaikan yang sesuai dengan peraturan yang berlaku. Hal tersebut tentunya wajib dimiliki oleh semua anggota masyarakat dalam negara yang berdemokrasi, yang dilatih sejak dini sesuai dengan perkembangan paradigma pendidikan yang berlaku. Perubahan paradigma pendidikan di abad ke-21 mengharuskan adanya perubahan pembelajaran yang menekankan penguasaan 4 soft skills "berpikir kritis, kolaboratif, kreatif, dan komunikatif" bagi dosen terutama dalam mengimplementasikan kurikulum sesuai Kerangka Kualifikasi Nasional Indonesia (KKNI) yang berlaku sekarang di Universitas Kanjuruhan Malang. Perubahan pola pikir dan pola tindak dalam mengelola kelas dan melaksanakan proses pembelajaran menuntut dosen untuk lebih kreatif dan inovatif sebagai bentuk peningkatan mutu layanan pendidikan khususnya layanan proses pembelajaran. Proses dan hasil pembelajaran perlu direncanakan, dilaksanakan, dan dievaluasi agar berkembang ke arah optimal.
Kemampuan komunikasi, sebagai salah satu soft skill yang harus dikembangkan sesuai dengan KKNI, adalah model penyampaian pendapat dalam sistem bernegara yang demokrasi. Komunikasi dengan cara yang santun dan sesuai undang-undang dengan basis empiris, tidak mudah dilakukan di era keterbukaan saat ini. Dibutuhkan rancangan atau model pembelajaran khusus untuk meningkatkan kemampuan tersebut menjadi lebih baik dan terasah, terutama untuk mahasiswa Program Studi PPKn sebagai wadah untuk mendidik mahasiswa yang mempunyai kompetensi keahlian di bidang kenegaraan dan demokrasi. Pendidikan Kewarganegaraan merupakan mata pelajaran atau mata kuliah yang wajib ditempuh oleh seluruh siswa ataupun mahasiswa di sekolah atau di perguruan tinggi di Indonesia. Hal ini senada dengan yang dikemukakan oleh Winataputra (2012: 2) bahwa: pendidikan kewarganegaraan dalam arti luas yakni sebagai wahana pendidikan yang dibangun untuk membina dan mengembangkan warga negara yang cerdas baik dalam latar subsistem pendidikan formal, nonformal dan informal, pada dasarnya sudah menjadi 
bagian inheren dari idea, instrumentasi dan praksis pendidikan nasional Indonesia. Berdasarkan penjelasan bahwa pendidikan kewarganegaraan sebagai wahana pendidikan bagi warga negara agar menjadi warga negara yang cerdas dan baik yang secara legal formal telah diimplementasikan di Indonesia.

Pendidikan

Kewarganegaraan di Indonesia pada hakikatnya merupakan pendidikan yang mengarah pada terbentuknya warga negara yang baik, cerdas, dan bertanggung jawab berdasarkan nilainilai dasar negara yaitu Pancasila. Selanjutnya Pendidikan Kewarganegaraan pada penjelasan Pasal 37 ayat (1) menyatakan bahwa "Pendidikan Kewarganegaraan dimaksudkan untuk membentuk peserta didik menjadi manusia yang memiliki rasa kebangsaan dan cinta tanah air." Maksudnya adalah Pendidikan Kewarganegaraan pada dasarnya merupakan pendidikan karakter agar warga negara Indonesia memiliki rasa nasionalisme yang tinggi, yang mencintai tanah air dengan segenap jiwa raga. Sebagaimana yang dikemukakan dalam Winataputra (2001: 5) bahwa secara konseptual epistemologis, pendidikan Pancasila dapat dilihat sebagai suatu integrated knowledge system yang memiliki misi menumbuhkan potensi peserta didik agar memiliki "civic intelligence" dan "civic participation" serta "civic responsibility" sebagai warga negara Indonesia dalam konteks watak dan peradaban bangsa Indonesia yang berPancasila. Penjelasan tersebut menerangkan bahwa Pendidikan Pancasila merupakan sistem pengetahuan yang terintegrasi dimana memiliki tujuan agar peserta didik bukan hanya memiliki pengetahun namun juga memiliki kecerdasan yang baik, partisipasi yang tinggi, dan juga rasa tanggung jawab yang besar. Selanjutnya Pendidikan Kewarganegaraan atau civic/citizenship education secara substansif dan pedagogis didesain untuk mengembangkan kompetensi warga negara yang baik, cerdas, dan bertanggung jawab dilandasi oleh nilainilai yang terkandung dalam Pancasila. Berdasarkan Pasal 1 UU No. 20 Tahun 2003 bahwa pendidikan kewarganegaraan terdiri dari dua kata yaitu Pendidikan dan Kewarganegaraan. Pendidikan adalah usaha sadar dan terencana untuk mewujudkan suasana belajar dan proses pembelajaran agar 
peserta didik secara aktif mengembangkan potensi dirinya untuk memiliki kekuatan spiritual keagamaan, pengendalian diri, kepribadian, kecerdasan, akhlak mulia, serta keterampilan yang diperlukan dirinya, masyarakat, bangsa, dan negara. Berdasarkan landasan di atas menunjukkan bahwa Pendidikan Kewarganegaraan adalah usaha sadar dan terencana yang dilakukan pemerintah agar warga negaranya secara khusus peserta didik dapan mengembangkan potensi dirinya demi masyarakat, bangsa, dan negara. Hal ini sejalan dengan pendapat Bunyamin Maftuh - Sapriya (2005: 321) menjelaskan bahwa Pendidikan Kewarganegaraan yaitu mata pelajaran Pendidikan Kewarganegaran adalah program pendidikan atau mata pelajaran yang memiliki tujuan utama untuk mendidik siswa agar menjadi warga negara yang baik, demokratis dan bertanggung jawab. Program Pendidikan Kewarganegaraan ini memandang siswa dalam kedudukannya sebagai warga negara, sehingga program-program, kompetensi atau materi yang diberikan kepada peserta didik diarahkan untuk mempersiapkan mereka mampu hidup secara fungsional 
Zamroni (2007: 137) mengatakan

bahwa pendidikan kewarganegaraan adalah suatu proses yang dilakukan oleh lembaga pendidikan dengan proses mana seseorang mempelajari orientasi, sikap, dan perilaku politik, sehingga yang bersangkutan memiliki political knowledge, awareness, attitude, political efficacy, dan political participation, serta kemampuan untuk mengambil keputusan politik secara rasional, sehingga tidak saja menguntungkan bagi diri sendiri tetapi juga bagi masyarakat. Berdasarkan penjelasan di atas menjelaskan bahwa pendidikan kewarganegaraan diharapkan dapat menjadikan seseorang memiliki political knowledge, awareness, attitude, political efficacy, dan political participation, serta kemampuan untuk mengambil keputusan politik secara rasional yang nantinya dapat diimplementasikan di dunia nyata.
Tempat penelitian dilaksanakan di Program Studi Pendidikan Pancasila dan Kewarganegaraan Universitas Kanjuruhan Malang. Waktu penelitian dilaksanakan pada tahun 2017. Penelitian ini bertujuan untuk meningkatkan kemampuan komunikasi mahasiswa melalui metode STAD dengan basis LSLC dengan cara diskusi dan perdebatan pada mata kuliah Teori Demokrasi. Mata kuliah Teori Demokrasi dipilih dengan tujuan untuk kemudahan aplikasi dan penalaran pada mahasiswa untuk berpikir kritis dan logis dengan dasar empiris yang sudah dilihat dan dipraktekkan sehari-hari. Penelitian ini menggunakan metode pendekatan penelitian tindakan kelas (PTK) mengadopsi siklus model Kemmis dan Taggart 6 (enam) langkah dengan tahapan Plan, Do, See pada masing-masing siklus dengan basis Lesson Study, untuk meningkatkan kemampuan komunikasi mahasiswa, dengan gambaran siklus sebagai

berikut:

\section{METODE PENELITIAN}

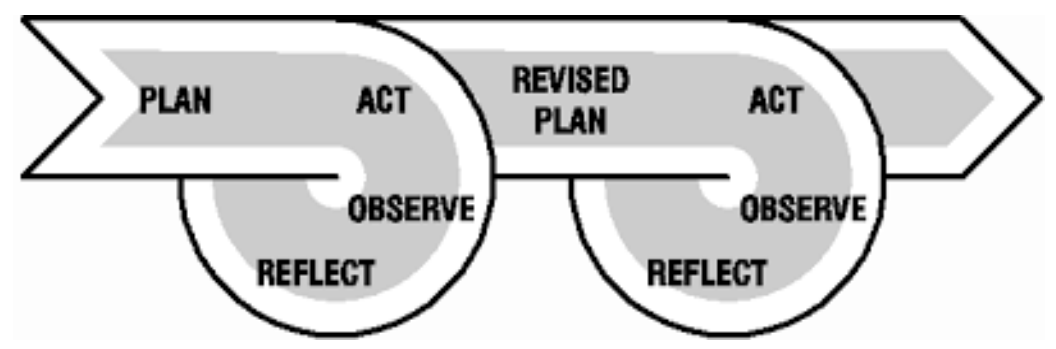

Gambar 1. Siklus Penelitian Tindakan Kelas 


\section{HASIL DAN PEMBAHASAN}

Pada tahapa Plan (perencanaan) tim pengembang matakuliah Teori Demokrasi berdiskusi terkait rencana pembelajaran yang akan disampaikan kepada mahasiswa. Kegiatan ini dilaksanakan dengan tujuan menentukan metode, media, dan bahan ajar yang tepat yang dapat digunakan dalam proses pembelajaran. Lesson Plan dan Chapter Design pada mata kuliah Teori Demokrasi dilaksanakan 4 hari sebelum kegiatan di kelas (open class).

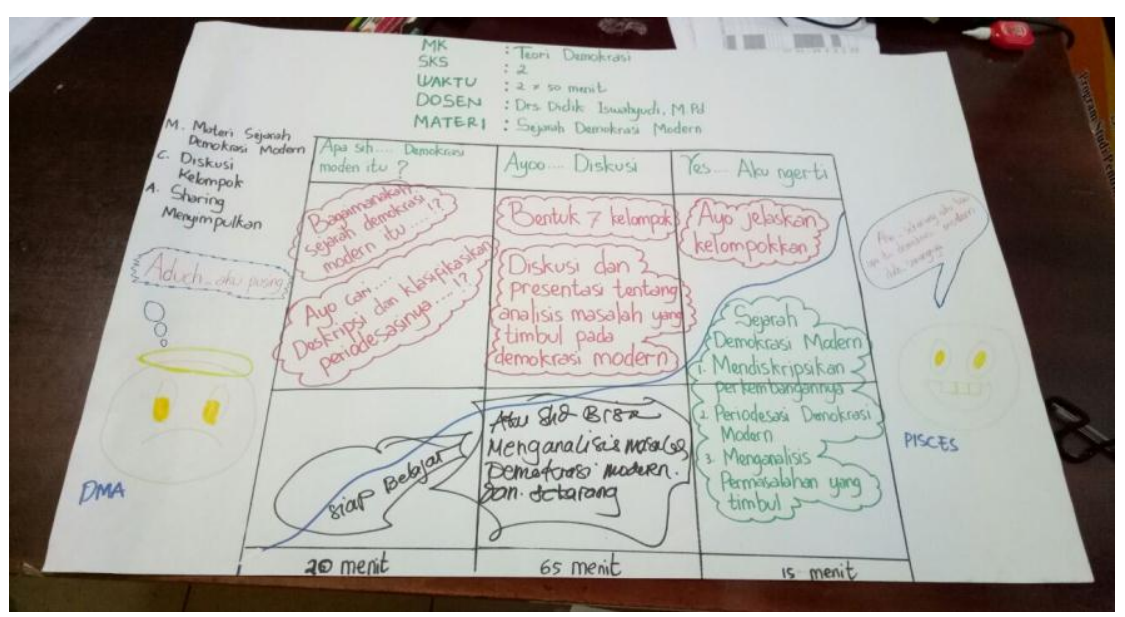

Gambar 2. Contoh Lesson Plan Teori Demokrasi Siklus 2

Pada tahap Do (pelaksanaan), pengampu mata kuliah mendiskusikan tim pengembang mata kuliah Teori hasil observasi, untuk memperoleh

Demokrasi melaksanakan tugasnya sesuai dengan job desk yang telah ditetapkan pada tahap plan yaitu untuk observasi pada tahap pendahuluan, inti, dan penutup pembelajaran. Dan tahap terakhir dari LSLC adalah tahap See (refleksi) yang merupakan tahapan untuk merefleksi kegiatan pembelajaran yang telah berlangsung. Tahap ini dosen feedback pengamatan dari observer, kekuatan, kelemahan, analisis hambatan dan kendala yang dialami, dan rekomendasi perbaikan dan saran untuk pelaksanaan selanjutnya, baik dalam tahap pelaksanaan, maupun kesesuaian dengan tahapan perencanaan yang sudah disusun baik untuk dosen pelaksana maupun mahasiswa. 


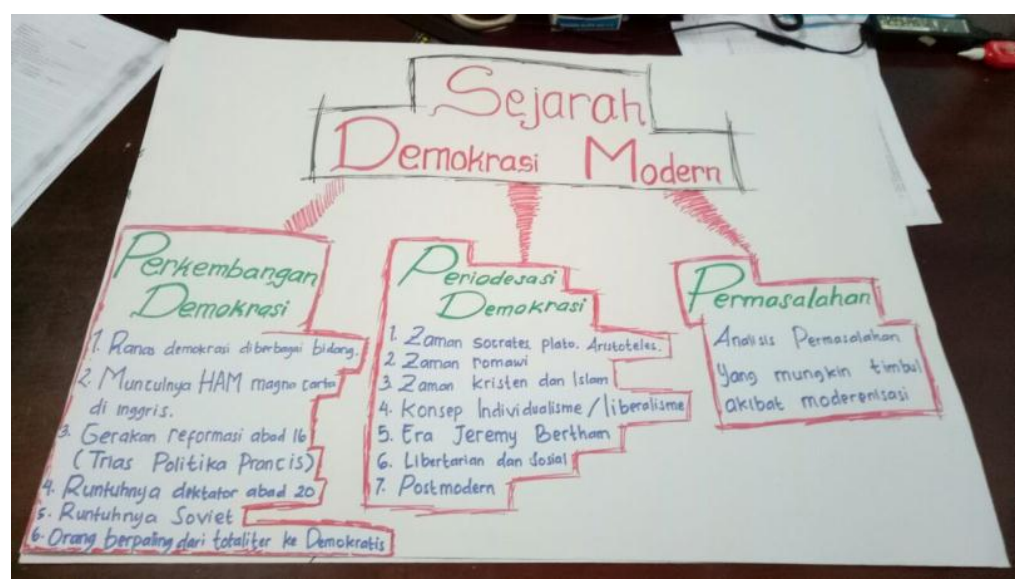

Gambar 3. Contoh Lesson Design Siklus 2

Pada siklus 1, pelaksanaan untuk diskusi berlangsung pasif dan mahasiswa masih kurang menguasai materi. Beberapa mahasiswa datang terlambat dan teamwork yang dilaksanakan di kelas juga berjalan kurang baik dengan mahasiswa yang diidentifikasi sebagai aktifis yang lebih menguasai diskusi di kelas. Perlu pembenahan pada aspek perencanaan dengan mengedepankan clue yang lebih update dan bahan diskusi yang lebih mudah dicerna dibandingkan dengan bahan Teori Demokrasi Klasik. Observer banyak memberikan kelemahan-kelemahan, terutama sektor perencanaan, dan intervensi dosen dalam pelaksanaan diskusi.

Pada siklus 2, pelaksanaan diskusi mulai berjalan dengan baik dan aktif. Mahasiswa yang aktif berkomunikasi mulai bertambah banyak, namun bahan diskusi masih belum berdasar dan empiris karena hanya mengandalkan nalar sebagai mahasiswa dan belum mendasarkan bahan diskusi pada bahan kajian yang mulai mudah dicarinya melalui internet. Ada mahasiswa yang terlambat dan masih pasif dan ramai sendiri kurang berminat dalam diskusi, sehingga perlu pembenahan dalam intervensi untuk aktifitas seluruh mahasiswa di kelas. Perencanaan selanjutnya adalah memberikan pembelajaran yang lebih efektif untuk mencari bahan diskusi yang empiris melalui internet yang mudah diakses. Observer mulai melihat keunggulan dan rancangan untuk komunikasi yang aktif dan memberikan banyak saran untuk perbaikan model diskusi pada siklus 3 .

Pada siklus 3, pelaksanaan pembelajaran mulai aktif dan mahasiswa yang aktif meulai berkomunikasi secara aktif meskipun 
dibantu oleh rekan satu tim. Mahasiswa mulai mampu berkomunikasi dan diskusi dengan bahan empiris melalui jurnal dan beberapa mahasiswa juga mulai memberikan bantuan untuk mencari sumber diskusi yang empiris. Mahasiswa datang tepat waktu dan mulai mandiri dalam membentuk kelompok diskusi dengan teamwork yang lebih baik. Perencanaan selanjutnya adalah diskusi yang diarahkan ke perdebatan. Observer melihat banyak melihat mahasiswa yang aktif komunikasi namun lemah dalam perdebatan secara empiris.

Pada siklus 4, pelaksanaan diskusi mulai diarahkan kepada perdebatan dengan masing-masing mahasiswa mulai aktif dalam mencari bahan diskusi yang empiris untuk dikomunikasikan dan diperdebatkan. Mahasiswa mulai mampu mencari kelemahan group lawan dan mulai saling menjatuhkan pendapat dalam berkomunikasi. Perdebatan berlangsung panas dan cenderung sengit. Tidak ada mahasiswa pasif dalam perdebatan, karena meskipun terdapat mahasiswa pasif dalam komunikasi perdebatan, namun sangat aktif untuk mencari bahan di internet dan berkomunikasi dengan baik dalam teamwork. Observer menyarankan perdebatan yang lebih terstruktur dengan panduan atau moderator yang lebih mengendalikan suasana perdebatan.

Pada siklus 5, pelaksanaan diskusi dimulai mandiri oleh mahasiswa, dan moderator yang mulai memperketat diskusi dan perdebatan. Tidak ada mahasiswa pasif, dan semua mahasiswa mampu mencari sumber perdebatan secara empiris melalui jurnal dan artikel yang dapat diakses dengan mudah lewat internet. Perdebatan mulai terstruktur, namun masih berlangsung dengan sengit. Beberapa mahasiswa masih sangat agresif mempertahankan pendapat dan masih banyak mahasiswa yang debat untuk melemahkan pendapat lawan debat dan bukan untuk mencari solusi perdebatan. Observer mengusulkan untuk lebih mengendalikan diskusi dan perdebatan kepada proses yang lebih terarah dan sistematis (masalah, problemsolving, rekomendasi) serta struktur debat yang mulai terukur timingnya.

Pada siklus 6, diskusi dan perdebatan mulai terarah dan terstruktur dengan baik. Komunikasi yang terjalin dalam diskusi dan perdebatan mulai menunjukkan hasil yang optimal dengan masing-masing kelompok tetap 
bertujuan untuk melemahkan pendapat tim lawan, namun dengan feedback dari masing-masing tim untuk penguatan diskusi dan perdebatan menuju problemsolving. Mahasiswa masih tetap agresif dalam mempertahankan pendapatnya masing-masing, dan masih berusaha menjatuhkan pendapat tim lawan. Observer memberikan saran untuk melatih moderator mahasiswa dalam mengendalikan suasana perdebatan yang lebih kondusif dan lebih terarah baik timing maupun content perdebatan.

\section{SIMPULAN DAN SARAN}

\section{Simpulan}

Berdasarkan pelaksanaan pembelajaran yang telah dilakukan, maka dapat disimpulkan bahwa:

1. Lesson study yang dilaksanakan secara esensi berjalan lancar dan tidak terkendala rintangan dan permasalahan yang menghambat penyelenggaraan pembelajaran.

2. Lesson study mampu memberikan efek positif kepada mahasiswa dan dosen pada proses pembelajaran yang meningkat dari pertemuan ke pertemuan.

3. Hasil observasi dan refleksi pada pelaksanaan kegiatan Lesson Study a. Aktifitas diskusi dan perdebatan pada kegiatan Lesson Study dari siklus I sampai dengan VI mengalami peningkatan yang signifikan, dengan dimulai dari diskusi yang pasif hingga perdebatan yang sengit dengan dasar pertimbangan yang mulai empiris pada mata kuliah Teori Demokrasi.

b. Group atau kelompok mahasiswa mengalami peningkatan, mulai dari diskusi yang pasif dan didominasi oleh satu kelompok, hingga perdebatan dengan kemampuan yang merata pada semua kelompok.

c. Aktifitas yang mulai disiplin dan dan tertib pada setiap siklus yang dilaksanakan oleh mahasiswa di tengah kegiatan magang.

\section{Saran}

Berdasarkan pelaksanaan pembelajaran yang telah dilakukan, maka saran yang dapat direkomendasikan adalah sebagai berikut:

1. Kebutuhan untuk meningkatkan kemampuan dan kapasitas 
penyusunan RPS dan RPP sesuai KKNI melalui workshop terpadu dan lokakarya.

2. Kebutuhan penyelenggaraan Lesson Study secara kontinyu untuk pemantapan dan penyempurnaan kualitas pembelajaran yang baik.

3. Pembagian nomenklatur dan volume kelas yang lebih representatif sehingga diskusi dan perdebatan lebih efektif dan efisien untuk proses pembalajaran yang baik.

4. Kegiatan Lesson Study dilaksanakan tidak hanya di dalam kelas saja namun juga dilaksanakan untuk praktek nyata di lingkungan laboratorium.

\section{REFERENSI}

Asma, Nur. 2006. Model Pembelajaran
Kooperatif.
Jakarta:
Departemen
Pendidikan
Nasional Direktorat Jendral
Pendidikan Tinggi.

Hasan, S. Hamid. 1994. Pendidikan Ilmu Sosial. Jakarta : Proyek Pendidikan Tenaga Akademik Dirjen Dikti Depdikbud.

Huda, Miftahul. 2011. Cooperative Learning: Metode, Teknik, Struktur dan Model Penerapan. Yogyakarta: Pustaka Pelajar.
Isjoni. 2013. Cooperative Learning Efektifitas Pembelajaran Kelompok. Bandung : Alfabeta.

Isjoni. 2010. Cooperative Learning. Alfabeta. Bandung.

Jarolimek, J \& Parker. 1993. Social Studies in Elementery Education (Sixth Edition). New York : Mac Milan Company.

Johnson \& Johnson. 1994. Cooperative Learning in The Classroom. Virginia, Association for Supervision and Curriculum Development.

Joyce, Bruce., Marsha Weil and Emily Calhoun. 2009. Models of Teaching. New Jersey: Person Education, Inc.

Jolliffe, Wendy. 2007. Cooperative Learning in the Classroom, Putting it into Practice. London : A SAGE Publications Company.

Lie, A. 2002. Cooperative Learning. Jakarta : Grasindo

Lie, Anita. 2004. Cooperative Learning, Mempraktekkan Cooperative Learning Di Ruang-Ruang Kelas. Grassindo, Jakarta.

Maftuh, B dan Sapriya. (2005).

Pembelajaran Pendidikan

Kewarganegaraan Melalui

Pemetaan Konsep. Jurnal Civicus 1, (5).

Ningsih, Ari Yunita. 2011. Penggunaan Media Kelereng dalam Model Pembelajaran Kooperatif (Think Pair Shre) untuk Meningkatkan Kemampuan Berhitung Perkalian Siswa 
Kelas II Sd Negeri 01 Dagen Jaten Karanganyar Tahun Pelajaran 2010/2011. Eprint. Uny. ac.id. (diakses pada 29 Maret 2015).

Prawiradilaga, Dewi Salma. 2008. Prinsip Disain Pembelajaran. Jakarta : Kencana Prenada Media Group.

Sanjaya, Wina. 2012. Media Komunikasi Pembelajaran. Jakarta: Kencana Prenada Media Group.

Sanjaya, Wina. 2009. Prencanaan dan Desain Sistem Pembelajaran. Jakarta: Kencana Prenada Media Group.

Sanjaya, Wina. 2011. Strategi Pembelajaran berorientasi standart proses pendidikan. Jakarta: Kencana Prenada Media Group.

Slavin, Robert E. 2009. Cooperative Learning Teori, Riset dan Praktik. Bandung: Nusa Media.

Slavin, R.E.1992. Cooperative Learning. USA : Allyn and Bacon

Sumar, Hendayana. 2009. Lesson Study Suatu Strategi Untuk Meningkatkan

Keprofesionalan Pendidikan. Bandung: Upi Press.

Suprijono, Agus. 2010. Cooperative Learning Teori dan Aplikasi PAIKEM. Yogyakarta: Pustaka Pelajar.

Trianto. 2010. Model Pembelajaran Terpadu Dalam Teori dan
Praktek. Jakarta: Prestasi Pustaka.

Warsono \& Hariyanto. 2012. Pembelajaran Aktif. PT Remaja Rosdakarya. Bandung.

Winataputra, Udin Saripudin (2012). Demokrasi dan Pendidikan Demokrasi. Jakarta:Gramedia Pustaka Utama.

Winataputra, Udin Saripudin \& Budimansyah, Dasim (2012). Pendidikan

Kewarganegaraan dalam Perspektif Internasional (Konteks, Teori, dan Profil Pembelajaran). Bandung: Widya Aksara Press.

Winataputra, Udin S. (2001). Pendidikan Demokrasi dan HAM. Universitas Terbuka. Jurnal Pendidikan Vol. 2 No. 1.

Zamroni. (2007). Pendidikan dan Demokrasi dalam Transisi. Jakarta: PSAP Muhammadiyah.

Marbun, Rosnita. 2013. Penerapan Model Cooperative Learning Tipe Think Pair Share Untuk Meningkatkan Aktivitas Dan Hasil Belajar Siswa Pada Pembelajaran Matematika Kelas IVa Sd Negeri 1 Panjang Selatan Bandar Lampung Tahun Pelajaran 2012/2013.Universitas Lampung. Bandar Lampung. 